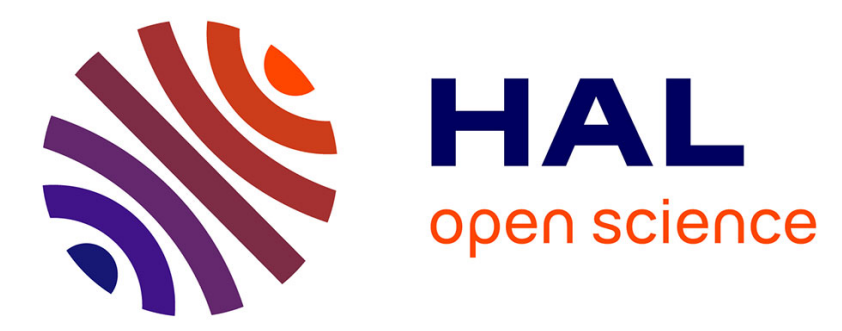

\title{
Transverse acoustic phonons in germanium near the melting point
}

B. Hennion, M. Schott

\section{To cite this version:}

B. Hennion, M. Schott. Transverse acoustic phonons in germanium near the melting point. Journal de Physique Lettres, 1984, 45 (12), pp.621-626. 10.1051/jphyslet:019840045012062100 . jpa-00232390

\section{HAL Id: jpa-00232390 https://hal.science/jpa-00232390}

Submitted on 1 Jan 1984

HAL is a multi-disciplinary open access archive for the deposit and dissemination of scientific research documents, whether they are published or not. The documents may come from teaching and research institutions in France or abroad, or from public or private research centers.
L'archive ouverte pluridisciplinaire HAL, est destinée au dépôt et à la diffusion de documents scientifiques de niveau recherche, publiés ou non, émanant des établissements d'enseignement et de recherche français ou étrangers, des laboratoires publics ou privés. 
Classification

Physics Abstracts

63.20D - 64.70D

\title{
Transverse acoustic phonons in germanium near the melting point
}

\author{
B. Hennion \\ Laboratoire Léon Brillouin, C.E.N. Saclay, 91191 Gif-sur-Yvette Cedex, France \\ and M. Schott \\ Groupe de Physique des Solides de l'E.N.S., Université Paris 7, Tour 23, \\ 2, place Jussieu, 75251 Paris Cedex 05, France
}

(Reçu le 14 mars 1984, accepté le 27 avril 1984)

\begin{abstract}
Résumé. - La dispersion des phonons transverses acoustiques du germanium dans les directions [111] et [100] a été étudiée jusqu'à $935^{\circ} \mathrm{C}$, deux degrés seulement au-dessous de la température de fusion $T_{\mathrm{m}}$. On ne trouve aucun amollissement ni de façon uniforme dans la Zone de Brillouin, ni près $\mathrm{du}$ bord de zone. Les énergies des phonons décroissent lentement et linéairement quand $T$ croît de $100 \mathrm{~K}$ à $T_{\mathrm{m}}$. Ceci suggère que la densité électronique à $T_{\mathrm{m}}$ est inférieure à $10^{21} \mathrm{~cm}^{-3}$. Les largeurs de raie des phonons sont très étroites jusqu'à $T_{\mathrm{m}}: \sim 0,035 \pm 0,015 \mathrm{THz}$, soit des durées de vie $\sim 10 \mathrm{ps}$ bien que les densités d'électrons libres et de phonons dans le cristal soient élevées près de $T_{\mathrm{m}}$.

Abstract. - The transverse acoustic phonon dispersion in germanium has been studied along [111] and [100] up to $935^{\circ} \mathrm{C}$, only 2 degrees below the melting point $T_{\mathrm{m}}$. No evidence of softening is found, neither near the Brillouin Zone boundary, nor uniformly throughout the BZ. The phonon energies decrease slowly and linearly with increasing $T$ from $100 \mathrm{~K}$ to $T_{\mathrm{m}}$. This suggests that the free electron density at $T_{\mathrm{m}}$ is less than $10^{21} \mathrm{~cm}^{-3}$. The phonon linewidths are very narrow up to $T_{\mathrm{m}}: \sim 0.035 \pm$ $0.015 \mathrm{THz}$, corresponding to lifetimes of the order of $10 \mathrm{ps,}$, although large densities of phonons and free carriers are present in the crystal near the melting point.
\end{abstract}

\section{Motivation for the study.}

Laser annealing of silicon or other semiconductors is a process of great potential technological importance [1]. The primary effect of laser irradiation is the creation of electron-hole pairs, which then can transfer their electronic energy to the lattice. Melting may occur as a conventional, " thermal », process. Several authors, however, have proposed a different mechanism, whereby, under high electronic excitation density, the electron-phonon interaction drives Transverse Acoustic modes to instability [2] before the lattice temperature reaches the usual melting temperature $T_{\mathrm{m}}$. Such an electronically driven instability leading to melting would be expected to occur for free electron densities of the order of a few $10^{21} \mathrm{~cm}^{-3}$, for atomic density $N \sim 5 \times 10^{22} \mathrm{~cm}^{-3}$.

Recently, Combescot and Bok [3] have calculated that the free electron density in Si should reach a few $10^{21} \mathrm{~cm}^{-3}$ at thermal equilibrium near $T_{\mathrm{m}}$, a much larger density than previously accepted; hence the possibility that melting of $\mathrm{Si}$, and germanium, could be the result of that new 
kind of instability. In support of the possibility that melting of $\mathrm{Si}$ and $\mathrm{Ge}$ has uncommon features, one may recall that, as is well known, the Lindemann parameters of these substances is smaller than that of common metals [4].

If melting is due to the above mentioned instability, TA mode softening should be observed near $T_{\mathrm{m}}$. Earlier calculations assumed a uniform softening of the TA modes throughout the Brillouin Zone, proportional to the free electron density $n$, according to

$$
\omega(q, n)=\left[1-\alpha n N^{-1}\right] \omega_{0}(q)
$$

where $\omega_{0}(q)$ is the dispersion relation in the absence of free carriers i.e. at $0 \mathrm{~K}, \alpha$ a proportionality constant and $N$ the atomic density. Using such an assumption, Heine and Van Vechten [5] were able to account quite satisfactorily for the temperature dependence of the energy gap in Si below $400 \mathrm{~K}$. That TA frequencies may become imaginary at large $n$ is illustrated by a former calculation by Martin [6]. Recently, Biswas and Ambegaokar [7], have put forward a theoretical calculation which, to some extent, interpolates between Martin's calculation and the approaches used to describe the phonon dispersion curves of group IV semiconductors in the absence of free electron effects [8]. They do not find a " uniform " softening as in equation (1); instead, softening occurs at the BZ boundary, first at point $L$, then at point $X$, for $n \sim 10^{22} \mathrm{~cm}^{-3}$. Again, this could lead to a structural phase transition, for instance melting. Measurement of the TA phonon dispersion near $T_{\mathrm{m}}$ may give information directly relevant to the melting process and, if softening is found, to laser annealing as well.

Ge should behave essentially as $\mathrm{Si}$, for which all the above mentioned calculations were done. Ge was chosen for the present study since it melts at a more accessible temperature $T_{\mathrm{m}}=937{ }^{\circ} \mathrm{C}$. Phonons in Ge have been studied extensively [9-13] : the TA mode frequency at point $L$ has been measured up to $430{ }^{\circ} \mathrm{C}$, other modes at various points up to $600{ }^{\circ} \mathrm{C}$; these temperatures are too low for anything related to the present problem to be expected, and indeed only a small and general softening of all modes, linear in $T$, was observed.

\section{Experimental setup.}

A $3 \mathrm{~cm}^{3} \mathrm{Ge}$ single crystal was mounted with [011] axis vertical between BN plates (in order to avoid any chemical interaction between $\mathrm{Ge}$ and its substrate) inside an evacuated furnace able to reach $1000{ }^{\circ} \mathrm{C}$.

The experiments were carried out on the 1T 3-axis spectrometer at the Orphée reactor of LLB, CEN-Saclay, using a Ge (111) monochromator and a pyrolytic graphite (002) analyser, and with horizontal collimations $25^{\prime} / 40^{\prime} / 50^{\prime} / 60^{\prime}$.

Attention was focussed onto the TA branches along the [111] and [100] directions, with a few measurements taken for comparison on the LA branch. In order to compare with previous results [10-13], some data were taken at $20^{\circ} \mathrm{C}$ and $600^{\circ} \mathrm{C}$. Measurements were then performed at 900 , 915 (where the most complete set of data was obtained) 925 and $935^{\circ} \mathrm{C}$. During the last run at $935^{\circ} \mathrm{C}$ the sample partially melted, providing a check of our $T$-scale $\left(T_{\mathrm{m}}=937^{\circ} \mathrm{C}\right)$.

In order to analyse the data, the variation with temperature and wavevector $Q$ of the intensity scattered outside the phonon peaks was studied and found to be proportional to the wavevector squared and to $T$ therefore corresponding to incoherent inelastic scattering related to the phonon density of states [14]. After subtraction of this intensity, the phonon peaks were fitted to a calculated lineshape, taking into account the known spectrometer resolution function, and assuming a damped harmonic oscillator for the phonon scattering cross-section. Additional assumptions in the fitting were : linear $Q$-dependence of the dispersion curve, constancy of the dynamical structure factor in the $Q$ region of the fit, neglect of phonon polarization. 


\section{Results and discussion.}

As an example of the data and fit, the neutron groups, measured at $900^{\circ} \mathrm{C}$ and $925^{\circ} \mathrm{C}$ for the TA phonon at point $L-\mathrm{BZ}$ boundary in [111] direction - are shown on figure 1 . The solid line is the profile calculated from the $925^{\circ} \mathrm{C}$ data with a frequency $v=1.728 \pm 0.002 \mathrm{THz}$ and linewidth $\Gamma=0.046 \pm 0.01 \mathrm{THz}$. The uncertainty in the frequency determination does not take into account a possible systematic shift which, from the comparison of our data to those published by Nelin and Nilsson [11-13], is less than $0.02 \mathrm{THz}$.

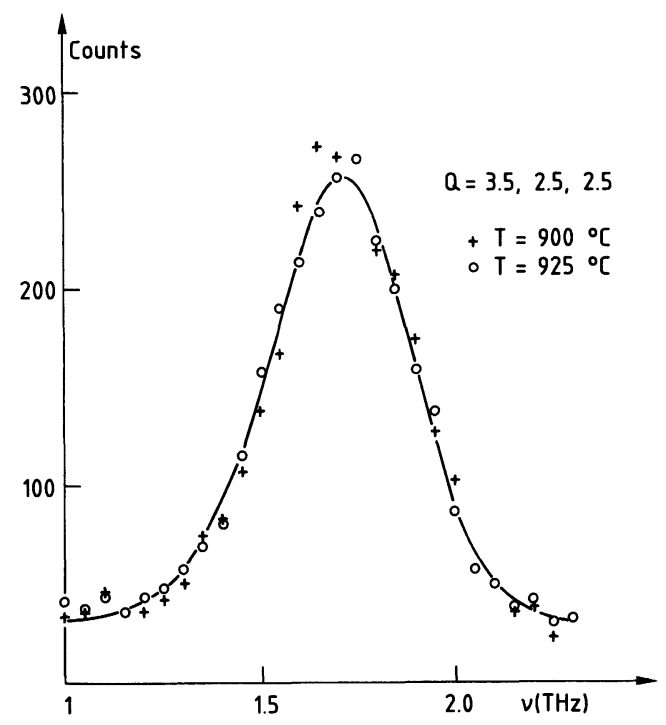

Fig. 1. - Neutron groups measured at the $L_{3}$ point $Q=(3.5,2.5,2.5)$ respectively at $T=900^{\circ} \mathrm{C}(+)$ and $T=925^{\circ} \mathrm{C}(\mathrm{O})$, with $k_{\mathrm{r}}=3.5 \AA^{-1}$. The straight line is the calculated profile for a damped harmonic oscillator with $\omega_{q}=1.728 \pm 0.002 \mathrm{THz}$ and $\Gamma_{q}=0.046 \pm 0.010 \mathrm{THz}$, fitted to the $925^{\circ} \mathrm{C}$ data.

An accurate determination of $\Gamma$, which is small in comparison to the instrumental resolution, is difficult to obtain. However, the average of all values obtained by fitting the data at all temperatures from $900^{\circ} \mathrm{C}$ to $935^{\circ} \mathrm{C}$ is $\Gamma=0.035 \pm 0.015 \mathrm{THz}$. The value found at $600{ }^{\circ} \mathrm{C}$ is slightly smaller, in agreement with the observation by Nelin and Nilsson [13], that « the linewidths do not exceed a few units of $0.01 \mathrm{THz}$ anywhere " (between 80 and $880 \mathrm{~K}$ ). The corresponding lifetime is of the order of $10 \mathrm{ps}$. Such a value at $900^{\circ} \mathrm{C}$ may be evidence of the smallness of anharmonic effects in Ge, even near $T_{m}$. It also sets a limit on phonon scattering by electronphonon interactions, near $T_{\mathrm{m}}$, that is in presence of electron densities in the range $2 \times 10^{19}$ to a few $10^{21} \mathrm{~cm}^{-3}$ [depending on the theoretical estimates, see Ref. [3] and discussion below].

Figure 2 shows the dependence of TA phonon frequency versus temperature, compared to data of reference [13], for points $L_{3}$ and $X_{3}$ at the BZ boundary, and for point $\left(\frac{1}{4} \frac{1}{4} \frac{1}{4}\right)$ on the lowest TA branch. All frequencies decrease linearly with increasing $T$ up to $T_{m}$, at approximately the rate of $(8.5 \pm 0.3) \times 10^{-5} \mathrm{~K}^{-1}$ found by Nelin and Nilsson [13]. This is particularly clear at $L_{3}$, where softening should occur first according to reference [7]. That the phonon frequencies found here at $X_{3}$ are below the linear extrapolation by $0.04 \mathrm{THz}$ might be due to a systematic error. A slight non-linearity in the variation of the frequency at this point cannot be excluded either. 

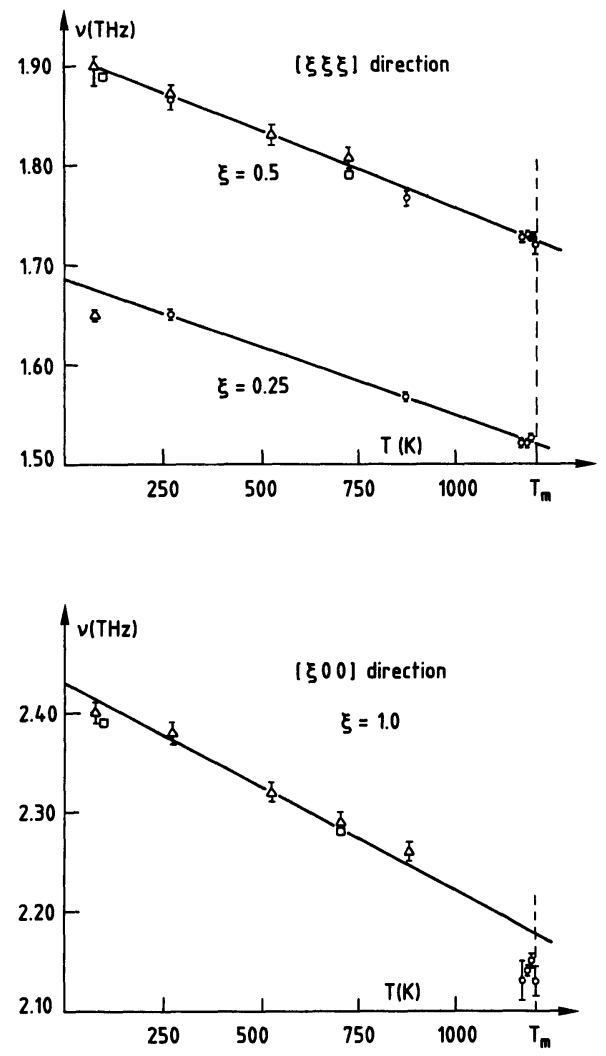

Fig. 2. - Phonon frequencies $v s$. temperature : a) in the $(\xi, \xi, \xi)$ direction for $\xi=0.25$ and $0.50 ;$ b) in the $(\xi, 0,0)$ direction for $\xi=1.0$. Circles correspond to the present experiment, triangles to Nelin and Nilsson measurements [13], squares to Brockhouse and Dasannacharya measurements [10]. The straight lines correspond to linear variations $\omega=\omega_{0}(1-K T)$ with $K$ values taken from Nelin and Nilsson, $8.2 \times 10^{-5}$ in the $(\xi, \xi, \xi)$ direction and $8.6 \times 10^{-5}$ in the $(\xi, 0,0)$ direction.

The dispersion of the TA [111] and [100] branches within the BZ has also been investigated. Figure 3 shows the data at $915^{\circ} \mathrm{C}$ (the data taken at 920 to $935^{\circ} \mathrm{C}$ were identical within our experimental uncertainty, see Fig. 1). Here again, there is no evidence of any softening at the BZ boundary. The arrows indicate the initial slopes of the phonon branches, calculated with $C_{11}=11.9, C_{12}=4.5$ and $C_{44}=6.2 \times 10^{11} \mathrm{dyn} / \mathrm{cm}^{2}$ obtained by linear extrapolation from room- $T$ value [15]. The agreement with experiment near the $\mathrm{BZ}$ centre further illustrates that the phonon energy temperature dependence is fairly uniform all along the branch, with a total energy change from $80 \mathrm{~K}$ to $1200 \mathrm{~K}$ of $\sim 10 \%$.

Finally, neither the temperature dependence of the neutron group integrated intensity, nor the $Q$-dependence of this intensity along the TA [111] or [100] branches show any anomaly near $T_{\mathrm{m}}$.

In summary, the study of the dispersion relation of the lowest TA branches in Ge up to its melting point gives no evidence of a softening which might be associated with a high free carrier density, anywhere in the BZ and especially at the BZ boundary. The linear decrease of all phonon energies with increasing temperature, already observed at lower $T$ [13], persists unchanged up to the melting point. It seems therefore that the postulated mechanism of melting via the influence of free electrons $[2,3]$ does not operate in Ge at thermal equilibrium near $T_{\mathrm{m}}$; rather, it is over- 


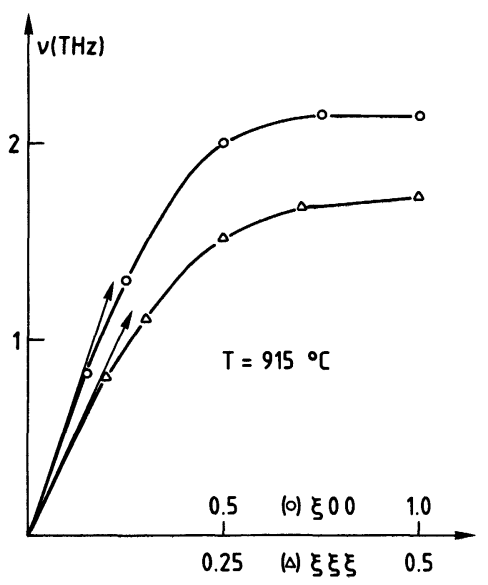

Fig. 3. - TA branches in the $(\xi, 0,0)$ direction $(O)$ and in the $(\xi, \xi, \xi)$ direction $(\triangle)$ at $T=915^{\circ} \mathrm{C}$. The initial slopes correspond to $C_{11}=11.9, C_{12}=4.5, C_{44}=6.2 \times 10^{11} \mathrm{dyn} / \mathrm{cm}^{2}$. The values found at $925^{\circ} \mathrm{C}$ are identical to those plotted on the figure.

come by a more common process before the carrier density is large enough. A direct measurement of this density just below $T_{\mathrm{m}}$ would clearly be desirable, and might allow to use the present data in the discussion of laser annealing processes. Equation (1) postulates a variation of $\omega(q)$, linear in $n$, uniform in $q$. The variation of $\omega(q)$ found here is uniform in $q$, but linear in $T$, of which $n$ depends exponentially. Thus, even at $T_{\mathrm{m}}$, only a minor fraction of the observed decrease in $\omega(q)$ may be associated to an electronic effect; an upper limit of $n\left(T_{\mathrm{m}}\right)$, within the theory of reference [5], can then be calculated : $\omega\left(T_{\mathrm{m}}\right) / \omega(R . T) \sim 0.9, \alpha=\frac{1}{4} f \varepsilon_{0} \sim 4$, since $f \sim 1$ and $\varepsilon_{0}=16$ neglecting variation of $\varepsilon_{0}$ with $T$. Therefore $n\left(T_{\mathrm{m}}\right)<10^{21} \mathrm{~cm}^{-3}$, much less than the densities invoked in the plasma melting theory of picosecond laser annealing [2]. $10^{21} \mathrm{~cm}^{-3}$ is also the critical density below which no effect of the free carriers on the phonon energies is predicted in (7).

The 10 ps TA phonon lifetime suggested by the observed linewidths indicates that the phonon distribution generated in picosecond laser annealing experiments might be far from thermal equilibrium, and different from that operative when nanosecond pulses are used.

\section{Acknowledgments.}

We thank M. Voos for the gift of the Ge crystal. Discussions with J. Bok, M. Combescot, P. Lavallard, J. P. Maneval and J. A. Van Vechten are gratefully acknowledged.

\section{References}

[1] See for instance, Laser and electron-beam processing of materials, ed. by C. W. White and P. S. Peercy (Acad. Press, N.Y.) 1980 ; Laser and electron-beam solid interactions and materials processing, ed. by J. F. Gibbons, L. D. Hess and T. W. Sigmon (North Holland, N.Y.) 1981 ; or the recent symposium : " Laser-Solid interaction", J. Physique Colloq. 44 (1983) C5.

[2] See for instance Van Vechten, J. H., J. Physique Colloq. 41 (1980) C4-15.

[3] Сombescot, M. and BoK, J., Phys. Rev. Lett. 42 (1982) 1413.

[4] BoK, J., Phys. Lett. A 84 (1981) 448. 
[5] Heine, V. and Van Vechten, J. A., Phys. Rev. B 13 (1976) 1622.

[6] Martin, R. M., Phys. Rev. 186 (1969) 871.

[7] Biswas, R. and Ambegaokar, V., Phys. Rev. B 26 (1982) 1980.

[8] For a recent discussion, see Weber, W., Phys. Rev. B 15 (1977) 4789.

[9] Brockhouse, B. N. and Iyengar, P. K., Phys. Rev. 111 (1958) 747.

[10] Brockhouse, B. N. and Dasannacharya, B. A., Solid State Commun. 1 (1963) 205.

[11] Nilsson, G. and Nelin, G., Phys. Rev. B 3 (1971) 364.

[12] Nelin, G. and Nilsson, G., Phys. Rev. B 5 (1972) 3151.

[13] Nelin, G. and Nilsson, G., Phys. Rev. B 10 (1974) 612.

[14] Marshall, W. and Lovesey, S. W., Theory of Thermal Neutron Scattering (Oxford U. Press) 1971.

[15] See for instance, Beilin, V. M., Velikov, Yu. Kh., Kadyshevich, A. E. and Krasil'Nikov, O. M., Sov. Phys. Solid. State 10 (1968) 1226. 